\title{
O AVANÇO DE INICIATIVAS DE GOVERNANÇA PRIVADA EM MERCADOS DE SUSTENTABILIDADE: O CASO DAS ROUNDTABLES GLOBAIS EM INSUMOS PARA BIOCOMBUSTÍVEIS
}

\author{
THE ADVANCE OF PRIVATE GOVERNANCE INITIATIVES IN SUSTAINABILITY \\ MARKETS: THE CASE OF GLOBAL ROUNDTABLES IN FEEDSTOCK FOR \\ BIOFUELS
}

\author{
Louise Nakagawa $^{1}$ \\ Arílson da Silva Favareto ${ }^{2}$ \\ Otto Hospes ${ }^{3}$
}

RESUMO

Os entraves socioambientais advindos do sistema produtivo, somados às fragilidades das políticas públicas e da ação pura dos mercados, resultaram no surgimento de um novo arranjo institucional constituído por agentes sociais e econômicos de diferentes áreas, dando origem a iniciativas multistakeholder. Denominada neste trabalho de governança privada, essas estruturas se referem às roundtables globais que tratam da elaboração de critérios de sustentabilidade por meio de sistemas de certificação. Inseridas em mercados que se apoiam em formas de uso de recursos naturais que se reivindicam sustentáveis, essas iniciativas têm avançado sobre diversos setores. Entretanto, ao analisar processos em governança privada, o que se nota é que a maior parte dos estudos está voltada para a interferência de fatores econômico-institucionais, e não em torno das relações sociais. Assim, buscouse aprofundar a compreensão sobre a dinâmica das roundtables globais a partir da abordagem político-cultural, apoiada na Nova Sociologia Econômica. Ao revelar as concepções de controle e o SAF, foi possível aprimorar o entendimento acerca do funcionamento e constituição das iniciativas de governança privada, e explicar a diferenciação das performances das três principais roundtables globais que tratam da produção de insumos para biocombustíveis: RTRS, RSB e RSPO.

Palavras-chave: Governança Privada, Sustentabilidade, Biocombustíveis

\begin{abstract}
Social and environmental barriers arising from the production system, added to the fragility of public policies and the action of markets, have resulted in the emergence of a new institutional arrangement consisting of social and economic agents from different areas, giving rise to multi-stakeholder initiatives. Named on this work as private governance, these structures refer to global roundtables dealing with the development of sustainability criteria through certification systems. Inserted in markets that rely on forms of natural resource

\footnotetext{
${ }^{1}$ Doutora em Energia pela Universidade Federal do ABC (UFABC). Pós-doutoranda no Departamento de Geografia e Planejamento da University of Liverpool. Email: louise.nakagawa@gmail.com.

2 Doutor em Ciência Ambiental pela Universidade de São Paulo (USP). Docente do Centro de Engenharia, Modelagem e Ciências Sociais Aplicadas da Universidade Federal do ABC (UFABC). E-mail: arilson.favareto@ufabc.edu.br

${ }_{3}$ Doutor em Agricultura e Ciêcnias Ambientais. Docente do Departamento de Ciências Sociais da Wageningen University. Email: otto.hospes@wur.nl
} 
that claim to be sustainable, these initiatives have advanced on many sectors. However, when analyzing processes in private governance, what we see is that most of the studies are focused on the interference of economic-institutional factors, and not around the social relations. Thus, it sought to deepen the understanding of the dynamics of global roundtables from the political-cultural approach, based on the New Economic Sociology. By revealing the conceptions of control and the SAF, it was possible to improve the understanding of the operation and establishment of private governance initiatives, and explain the differentiation of the performances of the three major global roundtables dealing with the production of feedstocks for biofuels: RTRS, RSB and RSPO.

Keywords: Private Governance, Sustainability, Biofuels

JEL: Z1; Q2

\section{INTRODUÇÃO}

Desde a crise do petróleo na década de 1970, a fragilidade dos setores produtivos passou a ser claramente observada sob dois importantes aspectos. $\mathrm{O}$ primeiro deles, associado à possibilidade de esgotamento dos recursos naturais, sobretudo, dos combustíveis fósseis. E o segundo, refere-se ao agravo dos impactos ambientais ao longo das últimas décadas, haja vista 0 aquecimento global e as mudanças climáticas. Os entraves presentes nas políticas públicas de diversas nações, somados às preocupações ambientais, resultaram em grandes encontros mundiais (Our Common Future,1987; The Earth Summit, 1992; Protocolo de Kyoto, 1997; Johannesburg Summit, 2002; Rio+20, 2012) com sérias exigências quanto à elaboração de medidas para diminuir os impactos causados pelos processos produtivos. Com isso, arranjos intergovernamentais foram criados na tentativa de reduzir as mudanças climáticas, salvaguardar a resiliência dos ecossistemas e proteger a biodiversidade, exercendo forte influência sobre os mercados.

As políticas socioambientais que até então eram reguladas somente pelos órgãos estatais, também passaram a ser definidas por instituições não estatais a partir da descentralização da autoridade, no intuito de minimizar os conflitos em torno da exploração e uso dos recursos naturais (CASHORE, 2002; CASHORE et al, 2004). Concomitantemente às discussões travadas acerca das variáveis ambientais, emergiu a retórica da sustentabilidade, e junto a ela surgiram apostas em novas tecnologias e propostas de reestruturação de diversos setores, inclusive de geração de energia. Neste percurso, os biocombustíveis se destacaram amparados no discurso de potencial sustentabilidade comparada aos combustíveis fósseis por serem capazes de cumprir positivamente, três requisitos: 1) ambiental, pois provêm de fontes renováveis; 2) social, porque permitem a inclusão de pequenos produtores na cadeia de suprimento, e; 3) econômico, já que podem gerar emprego e renda. Contudo, por trás dessas virtudes repousam outras três importantes controvérsias que questionam fortemente tal sustentabilidade: a) maior emissão dos Gases de Efeito Estufa (GEE), principalmente advindos dos 
impactos indiretos sobre os usos do solo; b) a exclusão dos smallholders ${ }^{4}$ da cadeia produtiva, e; c) a competição com cultivos para fim alimentar, colocando em risco o seu acesso pelos menos favorecidos.

Como forma de encaminhar os conflitos resultantes da produção dos insumos para estes combustíveis foram constituídas iniciativas multistakeholder com o objetivo de elaborar critérios de sustentabilidade mais eficientes que os mecanismos de comando e controle estatais, e que a ação pura do livre mercado. Dentro deste contexto, a emergência e o avanço das iniciativas de governança têm incentivado a participação e accountability ${ }^{5}$ de agentes sociais (TENDLER, 1998; BOSCHI, 1999; VALLEJO \& HAUSELMANN, 2004). Sua organização tem sido dada sob diferentes terminologias: instituições não estatais reguladas pelo mercado (non-state market driven) (CASHORE, 2002; CASHORE et al, 2004; BERNSTEIN, 2010); iniciativas multi-stakeholder (VALLEJO \& HAUSELMANN, 2004, O'ROURKE, 2006), e; parcerias privadas globais (global private partnerships) (SCHOUTEN \& GLASBERGEN 2011; HOSPES 2012). Denominada neste trabalho de governança privada, esta é uma estratégia que tem sido adotada em diversos segmentos (OSTROM, 1990; OSTROM, 2005; CASHORE, 2002; BERNSTEIN, 2010) como o Forest Stewardship Council (FSC) e o Marine Stewardship Council (MSC). Não diferentemente, o setor de insumos para biocombustíveis também se mobilizou com a criação de roundtables ${ }^{6}$ globais, compondo iniciativas como Roundtable on Responsible Soy (RTRS), Roundtable on Sustainable Biomaterials (RSB) e Roundtable on Sustainable Palm Oil (RSPO).

Seu maior diferencial está nas regras e estratégias de ação, determinadas por agentes não estatais guiados pela estrutura de mercado e por suas próprias trajetórias. Contudo, embora existam estudos empíricos em governança sobre diferentes temáticas, são poucos os trabalhos ancorados em abordagens teóricas explicativas, e menos ainda, referenciadas em fatores que não sejam estritamente econômicos e institucionais. Grande parte dos estudos que abordam o tema utiliza conceitos chave e elementos de análise voltados, sobretudo, para a ideia de legitimidade ${ }^{7}$ associada à Teoria Institucional, e a critérios de eficiência (WILLIAMSON, 1975; 1991) relacionados à redução dos custos de transação (OSTROM, 1990; ZYLBERSZTAJN \& FARINA, 2008), negligenciando fatores que auxiliam na compreensão das estruturas de funcionamento dos mercados.

Apesar dos esforços em torno da compreensão do funcionamento das iniciativas de governança privada, apoiados nos conceitos da Teoria Institucional ter importante contribuição, considera apenas as dimensões

\footnotetext{
${ }^{4}$ Os smallholders referem-se a grupos heterogêneos de produtores agrícolas categorizados de acordo com o setor no qual estão inseridos e são classificados conforme o tamanho do grupo, sua localização geográfica, seu poder de relacionamento entre mercados e seus artifícios institucionais (FAO, 2013).

${ }^{5}$ Accountability está relacionada à condição de responsabilidade dos agentes dentro da arena de ação.

${ }^{6}$ As roundtables são mesas redondas constituídas por agentes sociais e econômicos de diversos setores com diferentes interesses, mas que buscam a legitimidade de suas atividades a partir da transparência e da equidade em seus processos decisórios.

${ }^{7}$ De acordo com institucionalistas como Suchman (1995), a legitimidade é uma percepção generalizada de que as ações de uma entidade são desejáveis, próprias ou apropriadas em um sistema socialmente construído sob normas, valores, crenças e definições.
} 
econômico-institucionais em sua metodologia de análise ${ }^{8}$, e ignoram as variáveis políticas e culturais. Mesmo regidas sob a ideia de governança, a performance das roundtables não são semelhantes, haja vista as diferenças entre os agentes sociais que as compõem. Desse modo, a questão que se coloca é: como melhorar o entendimento acerca da dinâmica e do avanço das roundtables globais? E para isso, quais são os elementos teóricos que permitem explicar a diferenciação em suas performances?

Para compensar tal lacuna, a Nova Sociologia Econômica é capaz de oferecer interessantes abordagens teóricas com elementos explicativos de suma importância para o processo de análise das iniciativas de governança privada. Portanto, o objetivo deste trabalho é adotar elementos de análise mais adequados para entender a dinâmica e o avanço de três iniciativas globais que tratam da produção de insumos para biocombustíveis: RTRS (soja), RSB (biomateriais; antiga em biocombustíveis) e RSPO (óleo de palma), e assim, compreender de forma mais aprofundada e explicar o funcionamento desses arranjos institucionais em uma nova estrutura de mercado, como é o caso dos produtos certificados em sustentabilidade. Para isso, serão adotados os conceitos de concepções de controle e de Campo de Ação Estratégica (Strategic Action Field - SAF), referenciados na abordagem político-cultural, formulada por Neil Fligstein (1996; 2001; 2002) e Doug McAdam (2011; 2012).

\section{SOCIOLOGIA ECONÔMICA E ANÁLISE DOS MERCADOS}

Até a segunda metade do século $X X$, a constituição, emergência $e$ dinâmica dos mercados estiveram atreladas a fatores econômicos fundamentados na explicação de que os indivíduos sempre buscam maximizar seu bem estar e otimizar seus ganhos através de reputação e lucro. Contudo, esse pensamento passou a mudar nas décadas seguintes com o surgimento da concepção de sociologia dos mercados, sendo incorporado o comportamento dos agentes sociais ao seu funcionamento. Assim como nos sistemas sociais, os sistemas econômicos operam de acordo com as vontades dos indivíduos que estabelecem ações e acordos políticos uns com os outros e constroem culturas locais para guiar suas interações (GEERTZ, 1983). Para White (1981), a estabilização da produção é possível apenas se os agentes considerarem e aceitarem o comportamento mútuo daqueles que compõem o mercado. Logo, ao considerar outras motivações, além das racionais, pesquisadores buscaram entender de que modo as relações entre os indivíduos são capazes de organizar e estabilizar suas atividades no mercado. Segundo os sociólogos econômicos, os processos que envolvem mercados raramente são puros e a ação econômica é uma forma de ação social, cujas instituições por trás delas, são construções enraizadas em redes sociais (SWEDBERG \& GRANOVETTER, 1992; SPILMANN, 1999).

A partir de estudos com o objetivo de analisar a construção e funcionamento dos mercados, a Sociologia Econômica ramificou-se sob diferentes visões teóricas. Dentre as principais correntes destacam-se três. A primeira delas está pautada na ideia de embeddedness de Mark Granovetter, na qual todas as formas de interação econômica estão centradas nas relações

\footnotetext{
${ }^{8}$ Um dos principais estudos que vale a pena ser salientado é o de Cashore e colaboradores (2004), intitulado 'Governing through markets', no qual se apoia em fatores-chave: estrutura de demanda de mercado e à participação social na agenda de políticas do setor, para explicar a legitimidade do FSC em diferentes países.
} 
sociais (GRANOVETTER, 1985, 2005). Em outros termos, entre os indivíduos existem conexões, cujo autor nomeia de 'enraizamento relacional' e 'enraizamento estrutural' (GRANOVETTER, 1992). As redes de interação, ou networks, são o cerne para entender o funcionamento dos mercados, influenciadas constantemente pelo meio no qual estão inseridas, sendo extremamente dinâmicas. Já as instituições são como redes estáticas ('congealed networks') (GRANOVETTER, 1992). Ou seja, as instituições econômicas são caracterizadas pela mobilização de recursos e pela ação coletiva, e a dinâmica dos mercados está enraizada em redes sociais e instituições. Por conta disso, os fenômenos econômicos não podem ser observados nem analisados apenas por modelos matemáticos, devido a constante dinâmica existente entre agentes e instituições (BURT, 1983; ZELIZAR, 1983; BAKER, 1984; FLIGSTEIN, 1990).

Durante sua difusão, a ideia de embeddedness era considerada mais uma forma estrutural que cultural de análise; por se aproximar dos processos de mercado, das transações de business to business e da sociologia das organizações. Em detrimento disso, deixou de contemplar a dimensão cultural, que segundo DiMaggio (1994), dificulta a compreensão das negociações e a capacidade dos empreendedores sobre a construção de networks fora de seus domínios. Assim, autores sinalizaram que tal abordagem não considerava a análise sob o viés de fatores político-culturais, nem sobre os requisitos sociais de instituições econômicas, e de nenhum modo conceitualizava o processo de construção dessas arenas (ZELIZAR, 1988; ZUKIN \& DIMAGGIO, 1990; POWELL \& SMITH-DOERR, 1994; FLIGSTEIN, 1996).

A segunda corrente refere-se à teoria organizacional, associada à Nova Teoria Institucional, que vê no empreendedorismo, a possibilidade de criação de novos conjuntos de acordos sociais em campos organizacionais, com o apoio dos interesses dentro e fora da esfera estatal (DIMAGGIO, 1988; DIMAGGIO \& POWELL, 1991). Esse novo institucionalismo, atrelado a John Meyer, é centralizado nos aspectos culturais e cognitivos das organizações que parecem ser mais racionais do que realmente são (DIMAGGIO \& POWELL, 1991; SMELSER \& SWEDBERG, 2005). As principais ideias trazidas por essa abordagem se traduzem em fatores que dizem respeito à capacidade e às circunstâncias que os agentes obtêm ao reconhecer ou atuar sobre seus próprios interesses (DIMAGGIO, 1988). Pautados nessa teoria, estudos comparativos em indústrias foram realizados, mostrando que as interações entre o Estado e as empresas têm gerado uma cultura de produção única. Entretanto, embora seja amplamente empregada, a abordagem volta-se primordialmente para a construção de normas e regras, sendo notável a ausência das variáveis políticas no seu processo de análise (FLIGSTEIN, 1996).

E a terceira explicação teórica, defendida por Neil Fligstein, busca tratar do funcionamento dos mercados por meio da abordagem político-cultural. As organizações procuram por estabilidade, e a transformação das estruturas sociais é denominada pelo autor de 'mercados como políticas', possuindo dois aspectos. O primeiro deles é que a formação dos mercados faz parte da construção estatal, visto que a organização e a dinâmica das instituições são pautadas sobre aparatos e forças políticas regidas pela estrutura governamental. Quando colocadas em prática, essas regras de construção e intervenção são fatores decisivos para compreender como novos mercados 
surgem em determinadas sociedades (FLIGSTEIN, 1996). O segundo aspecto está nos processos que ocorrem no interior dos mercados e refletem dois tipos de projetos políticos: a luta pelo poder dentro de uma empresa, e a luta pelo poder entre diferentes empresas para controlar o mercado (FLIGSTEIN, 1996). Assim, Fligstein utiliza os movimentos sociais para caracterizar a dinâmica dos mercados durante sua criação ou crise. Para isso, o autor se apoia nos trabalhos de Pierre Bourdieu, que conceitualiza a economia, assim como as indústrias como um campo (BOURDIEU \& WACQUANT, 1992; BOURDIEU, 1997; FLIGSTEIN, 2001), no qual os indivíduos possuem uma organização e estrutura social próprias, e onde cada agente traz consigo seu habitus econômico, que influenciará em suas ações futuras a partir de experiências anteriores.

Diante das três diferentes abordagens da Nova Sociologia Econômica, brevemente apresentadas, é possível notar que as duas primeiras carregam limitações de viés político e cultural, ao negligenciar dois fatores que são considerados primordiais quando se pretende analisar relações sociais em determinado campo. Por outro lado, a terceira ideia proposta considera a luta pelo poder e as intervenções políticas como importante fator explicativo para as estruturas de formação dos mercados, de acordo com Fligstein (1996). Quando um novo mercado emerge, permite a criação de novos grupos ou a participação de outros, advindos de mercados paralelos. De modo muito semelhante, o mesmo ocorre com a organização de novos movimentos sociais, que enxergam a possibilidade de obter vantagem a partir da oportunidade política. O tamanho do grupo, seus recursos, a existência de oportunidades políticas de atuação, a presença de agentes estatais dispostos a negociar e, a capacidade de construir uma coalizão política em torno de uma identidade coletiva (MCADAM, 1982; SNOW et al, 1986; TARROW, 1994) são fatores determinantes para estabilizar as relações entre os agentes dentro do mercado.

Fligstein se utiliza dos movimentos sociais pelo fato de possuírem semelhanças ao processo de construção de políticas, pois permitem entender a emergência de novos mercados, já que se trata de relações sociais na qual os agentes de diferentes grupos tentarão convencer uns aos outros a seguir suas próprias concepções de mercado no intuito de estabelecer um campo de acordos. Esse tipo de estratégia é denominado pelo autor de concepções de controle, e podem se tornar compromissos políticos para garantir a estabilização de um mercado específico. No caso dos mercados que estão em fase de emergência, as concepções de controle podem ser múltiplas, porque advém da trajetória de agentes de outras organizações; sua estabilização dependerá de concepções de controle que promovam formas leais de competição, de modo que todos os participantes possam continuar atuando dentro daquele mercado, mas que por outro lado, também sejam aceitas pelos órgãos estatais. Essas concepções representam a identidade coletiva, cujo único objetivo é garantir o êxito das atividades do grupo no mercado (FLIGSTEIN, 1996).

\section{A IMPORTÂNCIA DAS CONCEPÇÕES DE CONTROLE NO ENTENDIMENTO DA EMERGÊNCIA DE NOVOS MERCADOS}


No decorrer do último século, as formas de análise sobre a dinâmica e estrutura dos mercados sofreram transformações com o estabelecimento de novos conceitos dentro da Sociologia Econômica como aparato teórico explicativo. A aproximação com os conceitos emprestados das Ciências Sociais convergiu em estudos voltados para entender a interação e 0 comportamento dos agentes sociais dentro dos mercados. Algumas abordagens destacaram-se com a construção da ideia de network e embeddedness; com a Teoria Organizacional, e; com a associação entre estruturação dos movimentos sociais e a organização das firmas. Ao citar, na seção anterior, os três tipos de visão ou tratamento teórico, a abordagem político-cultural remetida à concepção dos 'mercados como políticas' (FLIGSTEIN, 1996), mostrou-se mais abrangente ao ser capaz de prover elementos teóricos extraídos do entendimento dos mercados como campos de disputas sociais, através da construção de um conjunto de estratégias, denominadas concepções de controle.

Para Fligstein (1996), as concepções de controle referem-se à compreensão e percepção das estruturas de funcionamento dos mercados e permitem interpretar o comportamento dos agentes em seus espaços, de modo que possam controlar a situação na qual estão imersos. Ou seja, "são simultaneamente uma visão que permite aos agentes interpretar as ações uns dos outros e a reflexão sobre como o mercado é estruturado" (FLIGSTEIN, 1996, p.658); elas refletem os acordos que serão estabelecidos como princípios de organização interna entre os agentes, as táticas de competição ou cooperação, e a hierarquia ou determinação de um status no mercado. Portanto, o principal objetivo das concepções de controle é possibilitar a compreensão social da relação entre os agentes, evitando a concorrência através do sistema de preços, solucionando as questões políticas internas (WHITE, 1981). Para isso, os participantes precisam ter uma visão coerente da organização que possibilite simplificar a tomada de decisão. Logo, aqueles que convencem ou anulam os outros estarão aptos a definir, analisar e encaminhar os problemas nos seus próprios termos, sendo os líderes de suas organizações (FLIGSTEIN, 1987).

$\mathrm{Na}$ tentativa de aproximar as teorias sociais e institucionais sobre a análise dos mercados, não apenas sob o interesse econômico, mas político e cultural, pesquisadores têm desenvolvido ao longo das duas últimas décadas estudos no intuito de integrar os movimentos sociais e a Teoria Organizacional (FLIGSTEIN, 1990; MCADAM \& SCOTT, 2005), rejeitando a perspectiva tradicional de comportamento coletivo e a visão racionalista (MCCARTHY \& ZALD, 1973) em busca de revelar a estratégia de ação coletiva (Collective Strategic Action). Esse tipo de fenômeno está relacionado aos esforços que os grupos exercem para adquirir vantagens estratégicas por meio da interação com outros grupos, denominado por Fligstein e McAdam (2011) de SAF. Ao construir sua perspectiva de análise sobre a emergência, estabilização e crise dos mercados, e buscando legitimar o seu uso, Fligstein e McAdam se debruçam sobre um conjunto de quatro explicações teóricas que auxiliam na organização da sua metodologia de análise para entender e avaliar a estrutura organizacional $\mathrm{e}$, sobretudo, o funcionamento do mercado por meio da interação e dinâmica entre os agentes que o constituem.

A primeira explicação deriva da ideia de ação coletiva, dos movimentos sociais e da Teoria Institucional. Intitulado SAF, esse elemento é considerado 
como unidade fundamental da ação coletiva em uma sociedade; é condição determinada pelos agentes que interagem através da troca de conhecimento sobre suas próprias concepções do que é o campo. São as relações que ocorrem dentro da arena de disputas e as regras estabelecidas. O entendimento do SAF pode ser desdobrado em quatro aspectos. O primeiro deles trata da variedade de interpretações sobre os acontecimentos no campo (BOURDIEU \& WACQUANT, 1992). O segundo aspecto é que existe um grupo de agentes presentes, que detém mais e menos poder. O compartilhamento de interpretações sobre as regras diz respeito ao terceiro aspecto, e refletem o entendimento de quais são as decisões e acordos que fazem sentido para que haja interação entre os agentes. E o último aspecto trata da existência de um quadro interpretativo sobre as estratégias coletivas e individuais como um reflexo das ações de outros agentes.

Em suma, Fligstein \& McAdam (2011) assumem que a integração desses quatro aspectos se aproxima mais da compreensão das relações sociais que meramente da ideia de que os grupos seguirão os mesmos padrões de comportamento dos que obtém algum nível de êxito em suas negociações. Por conseguinte, o SAF pode ser considerado uma arena socialmente constituída, onde os agentes utilizarão de seus recursos e habilidades para obter vantagem (BOURDIEU \& WACQUANT, 1992; MARTIN, 2003; EMIRBAYER \& JONHSON, 2008).

A segunda explicação refere-se aos incumbents, challengers e às unidades de governança, como parte integrante do campo no qual as estratégias coletivas são determinadas. Se os mercados são considerados por Fligstein como políticas, o autor inicia sua análise a partir do tamanho (em termos de poder de tomada de decisão) dos participantes nesse mercado, uma vez que existem os grandes grupos, capazes de controlar com mais facilidade os recursos externos, como o sistema de preços e a legitimidade, e os pequenos grupos, que geralmente seguem o comportamento dos maiores (ou com maior poder). A distinção entre o peso desses participantes é essencial para analisar o campo.

Segundo os trabalhos de Gamson (1975), os incumbents podem ser caracterizados como agentes que possuem influência entre os demais e cujos interesses e visões tendem a refletir na constituição de uma organização dominadora sobre o SAF. Esses agentes conhecem seus competidores e buscam encontrar ações para controlar a situação na qual estão imersos (FLIGSTEIN, 1996; FLIGSTEIN, 2001). Sua posição é definida de acordo com suas manifestações e as regras geralmente os favorecem, já que suas decisões tendem a legitimar e garantir sua posição no campo (FLIGSTEIN \& MCADAM, 2011). Por outro lado, os challengers representam os menos favorecidos, porque possuem pouca influência entre os demais (FLIGSTEIN, 2001). São capazes de reconhecer a dinâmica do meio e traçar suas estratégias de acordo com a dos incumbents, além de articular alternativas às decisões tomadas, tendo a habilidade de observar e identificar novas oportunidades de mudança na estrutura e funcionamento do sistema. E as unidades de governança (que não estão relacionadas à esfera estatal) são responsáveis por fiscalizar o cumprimento das regras, facilitando 0 funcionamento do sistema. Estão associadas à legitimidade das atividades do mercado e, portanto, não podem ser neutras, uma vez que têm o papel de 
reforçar a lógica dominante, apoiando, por sua vez, os interesses dos incumbents (FLIGSTEIN \& MCADAM, 2011).

Estando condicionada à definição da identidade do grupo, ao status hierárquico entre os incumbents e challengers, e ao compartilhamento das concepções de controle que guiam os agentes, o mercado tende a se estabilizar. Em outros termos, essas condições são responsáveis pelos acordos políticos que resultarão da interação entre os participantes e que reproduzirão a posição de vantagem do grupo com relação aos outros. Com isso, agentes de diferentes grupos tentarão convencer os demais a seguir as suas concepções. Desse modo, surgem duas possibilidades de acordo. A primeira é que se um grupo obtiver poder e influência suficientes, tentará forçar a adoção e o cumprimento do seu ponto de vista. Mas, se houver diferentes grupos com poderes equivalentes, poderão ser formadas coalizões sobre suas concepções, que se tornarão compromissos políticos para trazer estabilidade entre os grupos dentro daquele mercado (FLIGSTEIN, 1996; FLIGSTEIN \& MCADAM, 2011). Contudo, cabe destacar que não existe oposição entre as ações dos incumbents e challengers no SAF, mas sim, a definição de quem é a coalizão dominante e quem é o grupo menos organizado, com menos poder.

A terceira explicação diz respeito às estratégias de ação utilizadas pelos agentes na busca por cooperação (FLIGSTEIN, 2001). São as habilidades sociais dos indivíduos ou dos agentes coletivos, sua capacidade cognitiva de observar e compreender os outros e o ambiente que permitirão definir as estratégias ou estruturas de ação (JASPER, 2004; 2006). Esse processo está relacionado à criação de identidades e coalizões políticas, tendo como objetivo promover o controle por meio do entendimento racional e emocional dos indivíduos. Essa ideia refere-se ao conceito de habitus, na qual o comportamento dos agentes está amparado em um depósito de sentimentos e motivações, assim como sobre um repertório de ações e estratégias. Como enfatizam Fligstein e McAdam (2011), os indivíduos sempre estão atuando estrategicamente através de suas habilidades sociais, mesmo em sistemas estabilizados, pois essa capacidade entre os incumbents auxilia na produção e reprodução de status quo. Segundo March (1961), um mercado consegue sustentar suas atividades se os agentes possuírem as habilidades necessárias para manter suas relações de concorrência, mas também a coalizão política.

Finalmente, o quarto aspecto está atrelado à 'amplitude do campo' (Broader Field Environment). É muito comum considerar apenas a dinâmica e a interação dos agentes que ocorre dentro do campo. Porém, esse ambiente sofre a interferência do meio externo, pois está enraizado em redes complexas e conectados a outros campos. Para caracterizá-los Fligstein \& McAdam (2011) definem ao menos três tipos de interferências. O primeiro deles está pautado na distância e proximidade; os campos próximos são aqueles que o SAF frequentemente sofre impactos e interferências, e os distantes, por definição, referem-se àqueles que não têm capacidade de exercer qualquer tipo de influência. A segunda distinção está na relação entre os campos verticais e horizontais, nos quais o fator de análise fundamenta-se nas formas hierárquicas entre aqueles que se situam próximos uns dos outros. Se estiverem conectados verticalmente, a interação é de autoridade e subordinação, mas quando dependem um do outro, sua interação é dada como horizontal. E por fim, o terceiro tipo trata de distinguir os campos estatais e não estatais, no qual os agentes estatais detêm a autoridade para intervir nas 
regras e são capazes de declarar a legitimidade e viabilidade sob os campos não estatais (FLIGSTEIN \& MCADAM, 2011).

A partir do entendimento do que são as concepções de controle e da constituição do SAF, observa-se que os fatores destacados auxiliam sobre o entendimento do comportamento dos agentes sociais em estruturas tradicionais de mercado. Todavia, quando se trata de um novo tipo de arranjo institucional como os processos em governança privada, qual conjunto de concepções de controle será estabelecido e aceito pelos participantes desse campo? No caso das roundtables globais em insumos para a produção de biocombustíveis, como a RTRS, RSB e RSPO - iniciativas multi-stakeholder que se amparam em critérios de sustentabilidade para estabelecer suas regras de produção e certificação - revelar quais são as concepções controle que regem esse campo e o SAF delineado pelos agentes, caracterizando-os e compreendendo o seu funcionamento por meio das relações entre os agentes, faz-se extremamente necessário para permitir explicar o seu avanço. Sendo assim, nas próximas seções, serão analisadas as três iniciativas à luz dos elementos propostos por Fligstein (1996) e Fligstein \& McAdam (2011).

\section{REVELANDO AS CONCEPÇÕES DE CONTROLE E O SAF DE PROCESSOS EM GOVERNANÇA PRIVADA: O CASO DAS ROUNDTABLES EM INSUMOS PARA BIOCOMBUSTÍVEIS}

\subsection{Roundtable on Responsible Soy (RTRS)}

A criação da RTRS ocorreu em 2006 a partir do diálogo entre produtores de soja, indústria e ONGs. Como parte do seu objetivo, a roundtable incentiva a melhoria do processo de monitoramento e a garantia do bom funcionamento da produção de soja, mobilizando a participação de outros agentes na tomada de decisão sobre a elaboração de critérios de sustentabilidade, traduzidos no sistema de certificação; estabelecida em 2009, mas readequada no ano seguinte. Ao longo de seus oito anos de existência, a RTRS passou por mudanças e conflitos entre os participantes, porém, continua sendo referência no setor. Ao caracterizar a roundtable, verifica-se que sua estrutura de governança está organizada em três câmaras: 1) produtores; 2) indústria, traders (negociantes) e financiadores, e; 3) representantes da sociedade. $O$ quarto grupo refere-se aos observadores; considerados como participantes externos; podem estar presentes nas Assembleias Gerais, porém, sem poder de voz e voto. Segundo os dados disponibilizados pela RTRS (2012), até 2013, o total de membros da iniciativa era de 168, divididos nas três câmaras destacadas (figura 1). 


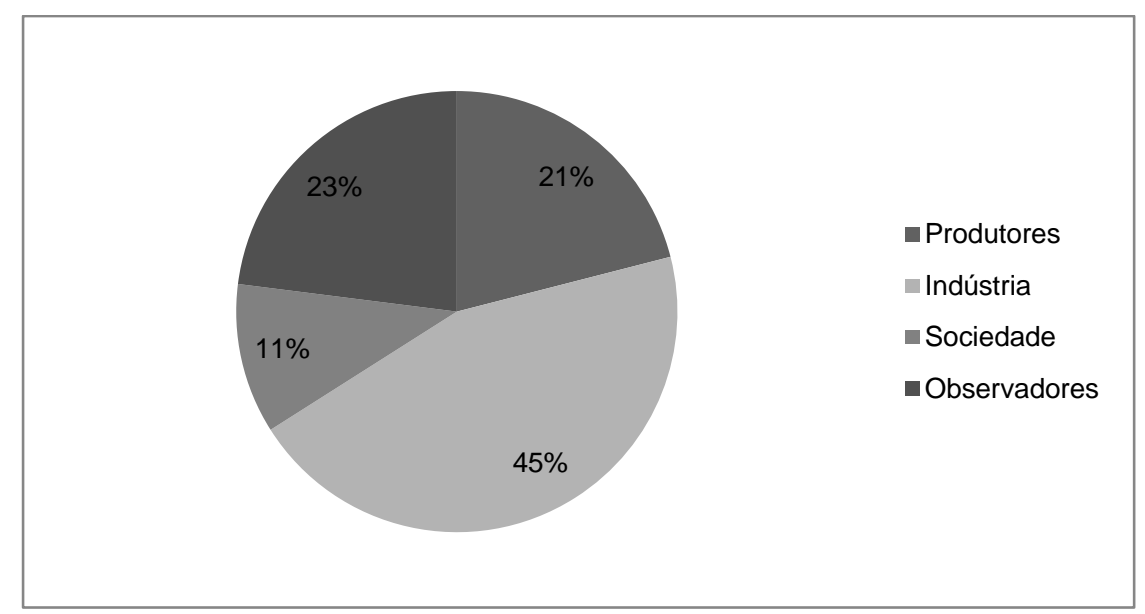

Figura 1. Distribuição percentual dos membros internos e dos observadores da RTRS (elaboração própria).

$\mathrm{Na}$ análise e caracterização dos participantes da RTRS, à luz da abordagem político-cultural referenciada na Nova Sociologia Econômica, foi possível identificar três categorias de agentes internos e não estatais: 1) os membros com maior poder de coalizão política, associados aos representantes dos grandes produtores e multinacionais que também fazem parte da Comissão Executiva; 2) os membros menos organizados que não possuem as habilidades sociais necessárias para impor seus interesses frente ao grupo, como é o caso dos pequenos produtores e representantes da sociedade, e; 3 ) os membros oposicionistas, sobretudo, os representantes da Associação Brasileira das Indústrias de Óleos Vegetais (ABIOVE) e da Associação dos Produtores de Soja e Milho do Mato Grosso (APROSOJA), que não aceitaram as regras estabelecidas e deixaram de compor a roundtable em 2009. Além destes, podem ser nomeadas duas categorias de agentes que não tomaram decisões, mas desempenharam importante papel no interior do campo e fora dele: a) os secretários executivos, que intermediaram os conflitos, buscando soluções mais adequadas, e; b) os observadores (entidades estatais e não estatais), responsáveis pelo financiamento da iniciativa, pelos estudos técnicos e desenvolvimento dos Princípios \&Critérios (P\&C) de Sustentabilidade.

Ao utilizar os elementos de análise desenvolvidos por Fligstein \& McAdam (2011), obtém-se dois cenários. O primeiro deles caracterizando os incumbents como grupo dos grandes produtores e de multinacionais, e os challengers como smallholders, representados pelos pequenos produtores e ONGs. Já o segundo cenário conta com membros europeus na posição de incumbents e sul-americanos, especialmente brasileiros, como os challengers, haja vista os conflitos ocorridos entre os participantes da ABIOVE e APROSOJA. Neste caso, a disputa pelo poder se deu entre dois grupos com forças equivalentes. Entretanto, os agentes brasileiros não tiveram poder de coesão suficiente para convencer os outros participantes sobre suas concepções. Por ser contrários e deixar a RTRS, ABIOVE e APROSOJA criaram a Soja Plus; iniciativa de governança privada de âmbito nacional, com o objetivo de desenvolver um programa participativo e transparente para atender as demandas do mercado de produtos sustentáveis (SOJA PLUS, 2013), que conta com a participação de membros produtores, governamentais, da sociedade, indústria e de pesquisa. 
Com destacada importância no campo, foram identificados os secretários executivos como representantes das unidades de governança. Mesmo não constituindo a bancada dos agentes tomadores de decisão, seu trabalho foi decisivo em diversos encontros, principalmente no processo de organização e estruturação da iniciativa. Porém, cabe salientar que essas unidades, no caso da RTRS, potencialmente dedicam-se mais que seus pares em estruturas tradicionais de mercado, pois por se tratar de iniciativas com adesão voluntária, os secretários executivos são contratados como funcionários, devendo, portanto, auxiliar na garantia sobre o êxito e funcionamento da roundtable. Assim, pode-se afirmar que mesmo os participantes externos exercem algum tipo de influência nas estratégias que são criadas e estabelecidas pelos tomadores de decisão, podendo ser sutil ou notória.

Sendo assim, ressalta-se a grande interferência que os observadores (considerados agentes externos) geraram no campo, principalmente no caso de ONGs e entidades governamentais que participaram como agências financiadoras, ou no processo de desenvolvimento dos P\&C de Sustentabilidade. Logo, percebe-se que quanto maior a proximidade entre os campos, maior é a interferência na dinâmica dos grupos presentes (FLIGSTEIN \& MCADAM, 2011). A amplitude entre campos, a princípio, mostra-se horizontalizada. A influência que os observadores detêm sobre os membros internos não se apresenta de forma hierárquica ou coerciva, mesmo porque, esses agentes apenas podem se pronunciar quando consultados. Entretanto, o cenário pode mostrar a existência de dois grupos. O primeiro é constituído por agentes que têm seus interesses voltados para o acompanhamento do que está ocorrendo dentro da roundtable, não havendo qualquer intenção em tornar-se membro atuante, como é o caso das empresas certificadoras. E o segundo grupo está associado às ONGs e entidades de pesquisa, que embora não atuem diretamente, auxiliam na melhoria dos padrões estabelecidos pela RTRS através de seus trabalhos técnicos. Ademais, observa-se a participação dos governos, principalmente holandês, no financiamento das atividades da iniciativa. Embora não atuem como membros internos, esses agentes influenciam em alguma medida no funcionamento da RTRS.

A partir da caracterização dos participantes da RTRS, o que se nota é que ao analisar a iniciativa, o SAF é fragilmente determinado. Isso é verificado pela ausência de uma identidade coletiva, haja vista os conflitos e a permanência de incertezas dos tomadores de decisão sobre o êxito e continuidade das atividades da roundtable, principalmente em torno do cumprimento dos critérios de sustentabilidade, ou da pouca adesão de novos membros. Outra evidência está na emergência de potenciais concorrentes. A Soja Plus é um exemplo disso. Serão estes grupos concorrentes futuros? E uma terceira evidência destaca a pouca adesão dos dois maiores produtores e compradores de soja mundiais: EUA e China, respectivamente. Se a RTRS foi concebida para atuar em âmbito global, o que se esperava, seria que tais países atuassem no grupo. No entanto, possuem um número reduzido de membros, com sua participação voltada especialmente para a câmara 2, no caso dos EUA (maior produtor mundial de soja) e a China no setor de produção (maior importador da commodity).

\subsection{Roundtable on Sustainable Biofuels (Atual Biomaterials) (RSB)}


A RSB foi concebida em 2006 a partir da união de ONGs, agências governamentais, setor privado e instituições acadêmicas, com o objetivo de criar um sistema padronizado global de P\&C de Sustentabilidade para a produção de combustíveis provindos de fontes renováveis de energia. Até a aprovação da primeira versão dos seus critérios, em 2008, a roundtable era integrada por uma Comissão Diretora soberana. Nesse período, a quantidade de membros internos era ínfima perto do número de participantes externos: vinte e três e quatrocentos e oito respectivamente. No ano seguinte, a estrutura de governança foi alterada; o poder concentrado na Comissão Diretora foi descentralizado em onze câmaras; cada uma com dois representantes votantes dentro na Comissão, com exceção da décima primeira (composta por entidades governamentais, acadêmicas, intergovernamentais). Mas, em 2010, estas câmaras foram reduzidas a sete, e uma versão mais atualizada dos P\&C de Sustentabilidade foi novamente aprovada pelo Conselho. Como resultado dos esforços, a iniciativa elaborou seu próprio sistema de certificação em 2011. Porém a roundtable passou por uma reestruturação no início de 2013, ampliando seu escopo para biomateriais.

Ao caracterizar a RSB, observa-se que sua estrutura de governança esteve organizada na Comissão Diretora, no Secretariado, nos GTs e em sete câmaras que representam: 1) produtores de insumos agrícolas; 2) produtores de biocombustíveis; 3) distribuidores, transportadores e investidores; 4) ONGs baseadas em direitos e sindicatos; 5) organizações rurais, indígenas e representantes de comunidades locais; 6) organizações ambientais; 7) organizações intergovernamentais, governos, consultorias. Dentre esses, apenas as câmaras 1-6 tinham poder de voto nos encontros do Conselho Diretor. A câmara 7 e os GTs podiam participar e discutir os temas apresentados nos encontros, assim como os secretários, convidados externos e o Diretor do Centro de Energia da Ecole Polytechnique Féférale de Lausanne (EPFL), mas não faziam parte do grupo tomador de decisão. De acordo com a RSB (2012), até 2013, a iniciativa era constituída por 100 membros, como mostra a figura 2. Para compor a Comissão Diretora são eleitos o chair e vicechair, um representando o grupo dos países desenvolvidos (norte) e o outro dos países em desenvolvimento (sul), e; um representante da indústria, e um membro acadêmico diretamente relacionado à EPFL. Já nos encontros do Conselho Diretor, as decisões são tomadas por meio do voto da Comissão Diretora e de dois representantes de cada câmara. Nesses encontros tanto os membros internos, como os participantes externos podem debater os temas expostos, mas fica excluído da votação o segundo grupo. 


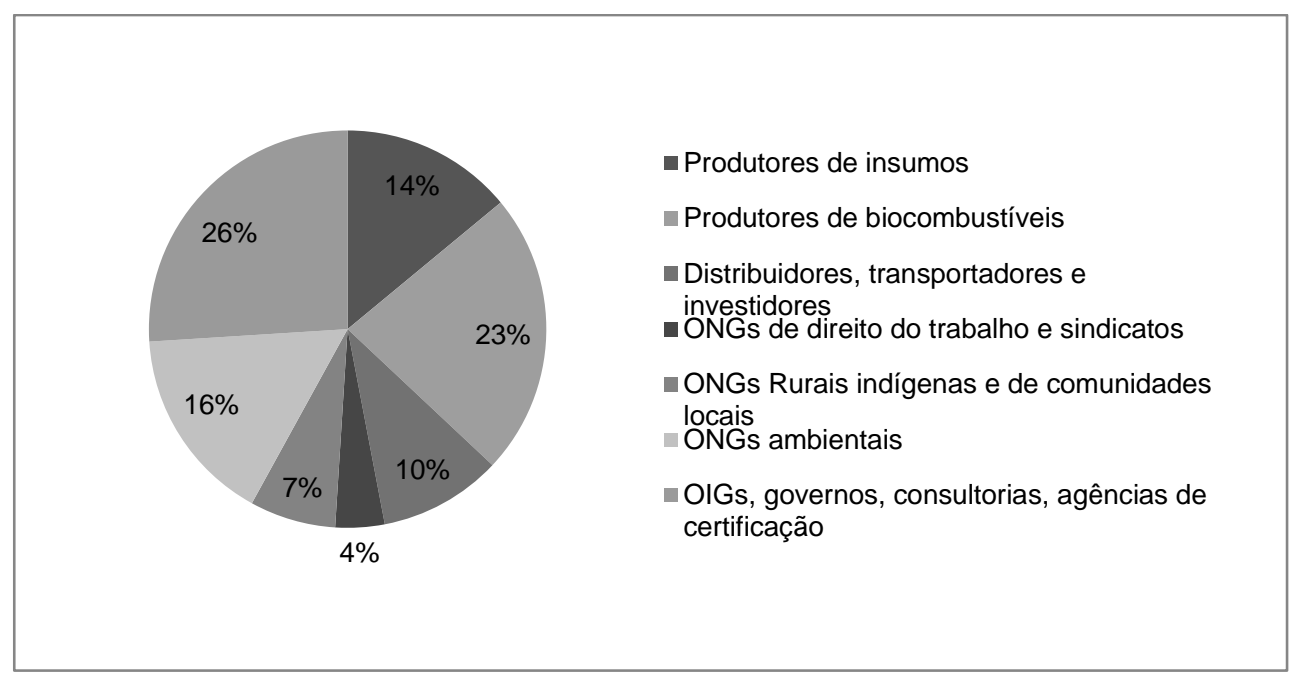

Figura 2. Distribuição percentual dos membros da RSB, de acordo com a câmara (elaboração própria).

$\mathrm{Na}$ análise à luz da abordagem política-cultural, sobre os participantes da RSB, foi possível identificar três categorias: 1) os membros internos não estatais pouco organizados e com poucas habilidades sociais, referentes aos representantes das câmaras 1-6, que embora polarizadas no bloco norte (composto em sua maior parte pelo setor privado) e sul (constituído por agentes de ONGs), não apresentaram características de conflito ou oposição, nem estão estruturadas sob forte coalizão política; 2) os participantes estatais e não estatais ligados à iniciativa sem poder de voto, mas com maior poder de coesão, associados à câmara 7, e; 3 ) os agentes externos, com menos poder de coesão, constituídos em sua maior parte por pesquisadores e acadêmicos. $\mathrm{Na}$ tentativa de categorizar os participantes da RSB, notou-se grande dificuldade em identificar os incumbents e challengers, pois, apesar de constituir-se como um processo em governança privada e por ser uma roundtable global, sua estrutura é completamente diferente da RTRS. Tal fato pode ser observado com a quantidade de câmaras e a diversidade de agentes presentes durante os encontros, influenciando, de algum modo, nos debates do Conselho Diretor, mas sem poder definir de maneira direta as regras estabelecidas por meio do voto.

Considerando somente os membros internos, ou seja, os agentes votantes, é possível dividi-los em dois grupos: a) os associados ao setor privado, composto em sua maior parte pelos países ricos, e; b) o grupo vinculado às ONGs, cuja maioria é advinda de países em desenvolvimento. Percentualmente, a quantidade de agentes do primeiro grupo é maior que a do segundo, mas como a representatividade pelos votos é equivalente, esse não poderia ser considerado um fator decisivo na identificação dos agentes em incumbents e challengers. Ao utilizar a metodologia de análise elaborada por Fligstein \& McAdam (2011) formaram-se dois cenários. O primeiro deles partiu da polarização existente entre o bloco norte e sul, no qual destacam-se as instituições privadas sediadas em países ricos como EUA, no papel de incumbents. Esta caracterização está vinculada à grande participação desses agentes em duas câmaras votantes, além do seu peso no processo de consulta regional, uma vez que os encontros foram amplamente divulgados nos EUA, ao contrário dos outros países consultados. Por outro lado, os challengers 
estariam associados às ONGs, constituídas por uma pequena parcela de agentes advindos do bloco sul (localizados na Ásia, África e América Central e do Sul).Tal fato também pode ser verificado através dos encontros regionais, nos quais foi notável a pouca participação dos representantes da sociedade, especialmente da Ásia e África.

Sob outro ponto de vista, a partir da avaliação das minutas registradas, constitui-se um segundo cenário, que ao contrário do que inicialmente imaginado, seria este composto pelos participantes da câmara 7, liderada principalmente por acadêmicos e pesquisadores (pertencentes a institutos dos EUA e Europa), e ao corpo de secretários, também associados a institutos de pesquisa (localizados no bloco norte), sobretudo à EPFL. Estes agentes, somados aos participantes externos, foram os principais responsáveis pela estruturação da iniciativa, pelos estudos técnicos e pelo desenvolvimento dos P\&C de Sustentabilidade da roundtable. Embora não tivessem poder de voto, desempenharam papel fundamental em todo o processo de evolução da iniciativa e foram capazes de convencer os representantes das outras câmaras e da Comissão Diretora, nos encontros do Conselho Diretor.

Sendo assim, setor privado e ONGs (câmaras 1-6) poderiam ser classificados como challengers, pois aceitaram, sem contestação, as propostas e sugestões estabelecidas pelo grupo acadêmico durante os encontros. A participação dos representantes de instituições acadêmicas e de pesquisa foi considerada pelos próprios membros da RSB um importante trunfo na garantia de legitimidade frente ao mercado internacional de biocombustíveis. Em outros termos, apenas um pequeno grupo deteve legitimidade perante os demais, garantindo o apoio tanto do setor privado como das ONGs sobre suas decisões. No papel das unidades de governança, como esfera facilitadora do funcionamento do sistema, observou-se a presença do Diretor do Centro de Energia da EPFL, Teddy Puttgen, presente em todos os encontros, na qualidade de convidado. Desse modo, a estrutura de governança da RSB, apesar de abrangente, mas limitada do ponto de vista do poder de voto, não só permitiu a interferência de agentes externos, como sustentou fortemente suas requisições sobre a importância dos conceitos e metodologias científicas adotadas.

A partir da alocação desses participantes nas categorias e cenários propostos, o que se nota é que a base da legitimidade da RSB está pautada no conhecimento tecnológico e científico, e na elaboração de um rol de critérios de sustentabilidade. Além disso, estão estreitamente implicados fatores econômicos como a posição no mercado (dependente de exportação ou importação do produto) e a existência de uma cadeia de suprimento bem organizada (CASHORE et al, 2004). Essas variáveis não podem ser negligenciadas quando se discute legitimidade face à exploração de recursos naturais e sustentabilidade em mercados internacionais. Isso pode explicar a variação entre incumbents e challengers dentro da RSB, visto que no caso de roundtables globais, não basta apenas classificá-los. Ainda é necessário observar que a luta entre forças ocorre, sobretudo, entre os maiores exportadores (especialmente os produtores norte-americanos) e os maiores importadores (principalmente indústria e traders europeus).

É notável que no caso da RSB, os participantes externos exerceram grande influência sobre as estratégias criadas e estabelecidas pelos tomadores de decisão. Ao avaliar a iniciativa, a amplitude entre os campos pode ser 
considerada horizontalizada. Mesmo não sendo votantes, os participantes externos eram continuamente convidados para compor a mesa de debates e podiam a qualquer momento, intervir nas discussões. Considerando que grande parte do que foi construído pela RSB veio de sugestões e recomendações de pesquisadores e acadêmicos, reforça-se mais uma vez o poder de coalizão política que esses agentes possuem. Ademais, observa-se que diferentemente do que a governança privada sustenta, entidades governamentais e intergovernamentais compõem o quadro de participantes da roundtable, e interferem nas decisões que são tomadas.

Por meio da caracterização e identificação dos agentes que constituem a RSB e da compreensão do rol de estratégias delineadas, foi possível observar que o SAF está estruturado no tipo de legitimidade que a roundtable busca conquistar frente ao mercado internacional de biocombustíveis. O que permite sustentar essa afirmação é a identidade coletiva, construída sob as habilidades sociais dos pesquisadores e acadêmicos que foram capazes de convencer os outros participantes a seguir suas concepções. Tal fato foi observado a partir da interferência desses agentes no processo de tomada de decisão, materializada nos $P \& C$ de Sustentabilidade e no sistema de certificação da RSB. No entanto, após oito anos de funcionamento, a roundtable passou por uma reestruturação no início de 2013, ampliando seu escopo, de biocombustíveis para biomateriais, e se desvinculando de sua sede na EPFL. Esse evento não gerou mudanças significativas na estrutura de governança da iniciativa, nem alterou sua identidade coletiva, já que não houve nenhuma cisão dentro do grupo. Mas cabe destacar que trata-se ainda de uma estratégia recente. Não se sabe ao certo em que medida será mantida. Para avaliar as implicações dessa mudança serão necessários alguns anos, o que determinará o êxito ou não das atividades da RSB no mercado internacional de biomateriais.

\subsection{Roundtable on Sustainable Palm Oil (RSPO)}

Criada em 2004, resultante da interação entre produtores do óleo de palma e a WWF, a RSPO deu início às discussões em torno da sustentabilidade da produção do insumo em 2003. Sua constituição teve como principal objetivo desenvolver e melhorar a produção do óleo de palma por meio da promoção de práticas sustentáveis em toda a sua cadeia produtiva, incentivando o compromisso e participação dos stakeholders, e prevendo a inclusão dos governos e consumidores no debate. Logo em 2005, o projeto piloto entrou em fase de implementação para averiguar a viabilidade e eficiência dos P\&C elaborados, iniciando os estudos sobre a rastreabilidade da cadeia produtiva e o acompanhamento do sistema de certificação. Ao final de 2007, estes critérios foram revisados e aprovados em Assembleia Geral, entrando em vigor no mesmo ano. Até 2013 a RSPO já era responsável por $14 \%$ da capacidade total de produção do óleo de palma no mundo, colocando em grande destaque a iniciativa.

A roundtable está estruturada em uma Comissão Executiva, composta pelo presidente, quatro vice-presidentes, o tesoureiro, dois membros honorários e dois representantes de cada câmara (mais os suplentes), com exceção da câmara dos produtores, que pode contar com a presença de quatro representantes (um da Malásia, um da Indonésia, um smallholder e um do 
"resto do mundo" - denominação dada pela Comissão Executiva); pela equipe de secretários que desempenha as funções administrativas, e; pelos GTs divididos de acordo com as seguintes temáticas: a) negócios e rastreabilidade; b) comunicações e reclamações; c) padronizações e certificações, e; d) finanças. Os participantes estão categorizados em Membros Ordinários (MOs) que detêm o poder de voz e voto durante as Assembleias Gerais e também podem estar vinculados aos GTs; os Membros Afiliados (MAs), que têm permissão para participar na qualidade de ouvinte, e; os Associados à Cadeia Produtiva, que não possuem participação ativa na RSPO (esse grupo apenas cumpre os P\&C estabelecidos) (figura 3). Dentre os MOs, estão organizadas sete câmaras: 1) produtores; 2) processadores; 3) consumidos de manufaturados; 4) varejistas; 5) bancos e investidores; 6) ONGs ambientais, e; 7) ONGs em desenvolvimento social (figura 4).

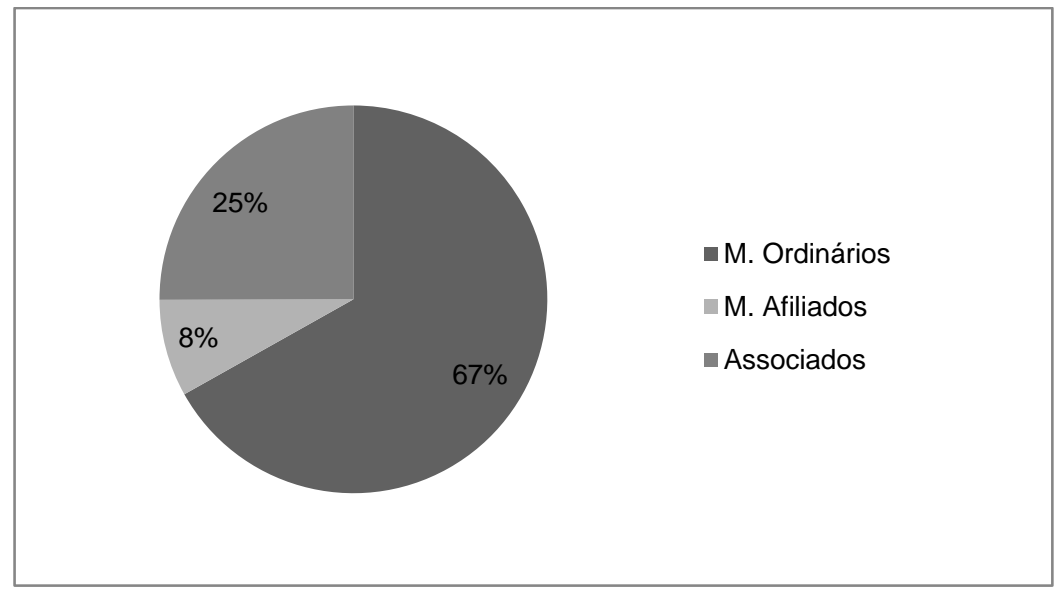

Figura 3. Distribuição percentual dos participantes da RSPO (elaboração própria).

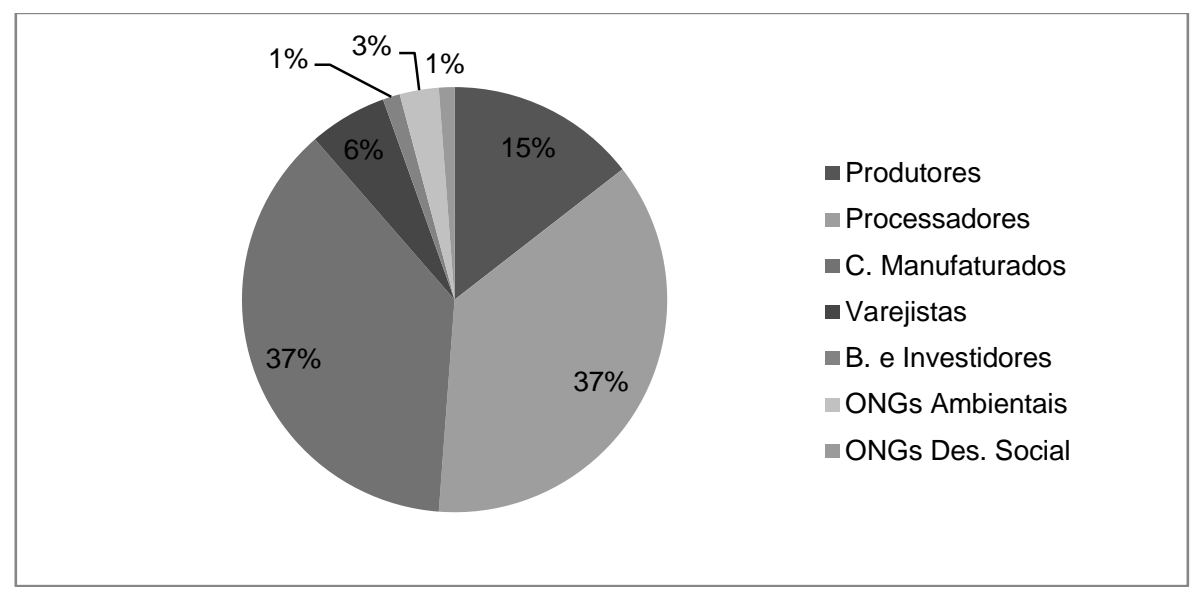

Figura 4. Distribuição percentual dos MOs da RSPO, de acordo com a câmara (elaboração própria).

$\mathrm{Na}$ avaliação dos participantes da RSPO, foi possível identificar quatro categorias de agentes: 1) os membros internos não estatais com grande poder de coesão, associados ao setor privado (que correspondem pela maioria dos MOs) e às ONGs globais (como WWF e Oxfam); 2) os membros internos não 
estatais organizados, mas com pouco poder de coesão, referentes aos smallholders, varejistas e investidores; 3) os participantes externos estatais com maior poder de coesão e importante influência sobre a Comissão Executiva, especialmente representados pelos governos indonésio e malásio, e; 4) os participantes externos não estatais pouco organizados e sem poder de coesão, atrelados aos MAs e afiliados. Diferentemente das duas roundtables anteriormente analisadas, a RSPO possui uma organização bem delimitada, com agentes que detém papéis determinados da iniciativa. Considerando apenas a primeira categoria de agentes, é possível classificá-los como incumbents, haja vista a atuação dominante perante os demais. Esta classificação pode ser desdobrada em três subcategorias: a) os MOs do setor privado relacionados às grandes indústrias processadoras e consumidoras do óleo de palma; b) os MOs do setor privado relacionados aos grandes produtores da Malásia e Indonésia, e; c) os MOs de ONGs socioambientais globais. Os três grupos possuem relevantes habilidades sociais, pois são capazes de convencer os outros participantes a seguir suas concepções. Embora dividam a mesma posição de dominação no campo, o que se nota é que existe forte disputa, principalmente entre os dois primeiros grupos, constatada pelas das contestações e tentativas de alteração do regimento interno sobre e escolha do presidente da Comissão Executiva.

É bastante interessante 0 tipo de interação que a câmara de processadores (2) e consumidores (3) tem com os produtores (destacando que o primeiro grupo está fundamentalmente constituído por empresas europeias e norte-americanas e o segundo é composto pelos asiáticos: Indonésia e Malásia), pois mesmo com a oposição dos produtores (1) às decisões tomadas pelas câmaras 2 e 3, há uma espécie de compensação da Comissão que beneficia os membros indonésios e malásios. Exemplo disso é a criação dos cargos de membros honorários para os representantes dos dois países, além da instalação de um escritório na Indonésia. No caso da RSPO, esses grupos são dependentes uns dos outros por duas razões: a) econômica, pois aqueles que produzem o insumo precisam de compradores e esses, por sua vez, precisam do produto para manter suas atividades, e; b) institucional, visto a enorme importância da estabilização de suas relações como forma de mostrar sua legitimidade. Não obstante, ainda existem os representantes das ONGs globais, que embora estejam em número reduzido demonstraram sutil, mas determinante, habilidade social ao estabelecerem suas concepções sem a necessidade de conflitos. Do ponto de vista socioambiental, acerca da ideia de sustentabilidade, esses agentes oferecem credibilidade à roundtable, o que gera benefícios para os agentes econômicos inseridos no campo. Por conta da posição estratégica face ao exigente mercado internacional, esses três tipos de incumbents foram capazes de constituir um grupo multi-stakeholder. E com isso, a iniciativa buscou manter sua legitimidade, evitando o surgimento de iniciativas concorrentes.

Em vista da pouca organização e coalizão política observada na tímida intervenção dos smallholders, sobretudo, advindos de países da América Latina e África durante as Assembleias Gerais, esses agentes foram classificálos em challengers. Entretanto, não são os únicos a compor tal categoria. Os varejistas, bancos e investidores, apesar de estarem aparentemente em um patamar favorável, não tiveram atuação dominante ou de destaque nos encontros da Comissão Executiva, nem nas assembleias; apenas seguiram as 
decisões tomadas pelos incumbents. Mesmo quando solicitada a criação de uma câmara diferenciada para acomodar os Mas às organizações transnacionais, sua proposta foi rejeitada pelos outros membros da iniciativa. Comparativamente, os smallholders, ainda apresentam maior organização política que os representantes das câmaras 4 e 5 . Isso pode ser observado com da aprovação das resoluções que beneficiavam o grupo como a redução da taxa de anuidade da RSPO e a ajuda de custo para obter a certificação de seus produtos, no caso dos pequenos produtores. E ao contrário das outras roundtables aqui analisadas, os secretários da RSPO não desempenharam papel central no auxílio do estabelecimento de estratégias, mas ainda assim, puderam ser consideradas unidades de governança, uma vez que atestaram as determinações feitas pelos.

Com a identificação dos membros internos, pôde-se constatar que apesar de ser uma iniciativa estruturada sobre a ideia de business to business, a RSPO assegura a legitimidade de suas atividades. Contudo, essa legitimidade não ultrapassou os limites que cercam a roundtable, como mostra o estudo de Schouten \& Glasbergen (2011). Para os autores, as variáveis legais e morais foram suficientes para aumentar a participação dos membros, mas não seu comprometimento sobre a produção sustentável do insumo, já que a adesão é voluntária e, portanto, não existem obrigações. Este fato resultou no enfraquecimento de tal legitimidade perante o mercado global de óleo de palma; observado com a não aderência de outros stakeholders (SCHOUTEN \& GLASBERGEN, 2011). Assim, nota-se a relevância da legalidade e da justificativa moral como fatores que também devem estar presentes no processo de análise das roundtables globais, especialmente por essas estruturas de governança dependerem, fundamentalmente, de legitimidade para estabilizar o seu funcionamento no mercado.

Neste sentido, verifica-se a influência que os agentes externos exercem sobre o campo de disputas. No caso da RSPO, a interferência foi direta, sendo interpretada de duas maneiras. A primeira delas pode ser explicada pela abertura da Assembleia Geral aos MAs, associados e governos. Ou seja, esses agentes têm poder de voz, podendo fazer intervenções e questionamentos durante os encontros, o que mostra a transparência da tomada de decisão. E a segunda, trata da forte presença dos agentes estatais vinculados à iniciativa, principalmente dos governos da Indonésia, Malásia e Holanda. Os dois países asiáticos possuem significativa posição entre os membros que constituem a RSPO, evidenciada na quantidade de plantações gerenciada por ambos (na Malásia, o Estado é responsável por aproximadamente $40 \%$ das companhias produtoras de óleo de palma).

Amparando-se nos elementos de análise desenvolvidos por Fligstein \& McAdam (2011), observa-se que o grau de proximidade entre os campos de agentes internos e externos é grande, o que permite maior interferência sobre as estratégias estabelecidas pelos tomadores de decisão. No entanto, esta relação não pode ser considerada totalmente horizontalizada, tampouco livre da intervenção mais expressiva dos agentes estatais. Ao observar as interações entre os participantes através dos registros das minutas, constata-se a autoridade que os governos da Indonésia, mas especialmente a Malásia, têm sobre o campo de disputas e sobre as decisões tomadas. Por meio da análise, à luz da abordagem político-cultural, nota-se que o SAF ampara-se na garantia sobre o êxito da roundtable pela rastreabilidade da cadeia produtiva e 
certificação do óleo de palma. O SAF voltado para business to business, mas com marcante presença de ONGs socioambientais globais, permite a construção de uma identidade coletiva muito próxima da ideia de governança, porém, sem se distanciar dos interesses econômicos do mercado. Em contrapartida, é forte a presença de agentes estatais na estrutura da iniciativa; que do ponto de vista do funcionamento dos mercados, é extremamente positivo (FLIGSTEIN, 1996). Embora a RSPO apresente certas vantagens, a roundtable ainda precisa descentralizar sua atuação altamente concentrada na Indonésia e Malásia. Como alguns membros sinalizaram nos encontros da Comissão Executiva, existem importantes agentes econômicos como China e Índia, que deveriam estar mais presentes, além da inserção de agentes da América Latina e África. Ao expandir suas atividades para outros continentes, a RSPO teria mais chances de alcançar legitimidade no mercado global de óleo de palma.

\section{CONSIDERAÇÕES FINAIS}

A ideia em aprofundar a compreensão sobre a dinâmica e avanço das roundtables globais nos mercados de sustentabilidade, explicando a diferenciação na performance das iniciativas de governança privada, por meio da adoção de abordagens teóricas amparadas na Nova Sociologia Econômica, se mostrou bastante interessante e adequada. Com isso, foi possível aprimorar e expandir o processo de análise em torno deste novo tipo de arranjo institucional, extrapolando os limites da metodologia usualmente utilizada, apoiada apenas em critérios econômicos e institucionais. Dentre as três principais correntes teóricas da Nova Sociologia Econômica, a abordagem político-cultural postulada por Fligstein (1996; 2001; 2002) foi escolhida para ser aplicada aos casos das roundtables globais que tratam da produção de insumos para os biocombustíveis. Por considerar fatores para além da avaliação estrutural ou organizacional das relações entre os agentes, seus elementos de análise possibilitaram ampliar a compreensão em torno da dinâmica das iniciativas de governança privada sob a perspectiva política e cultural no processo de tomada de decisão. Seus elementos empíricos, voltados para a revelação das concepções de controle e do SAF representaram um importante ganho no aprofundamento em estudos relacionados ao funcionamento e emergência desta nova estrutura de mercado, haja vista os resultados deste trabalho acerca das análises realizadas sobre RTRS, RSB e RSPO.

Analisando o funcionamento da RTRS, foi possível verificar que a iniciativa não possui uma identidade coletiva. Os incumbents como grupo dominante e com poder de coalizão política dentro do campo não foram capazes de sustentar suas concepções diante dos outros participantes. Isso foi observado por meio dos questionamentos em torno das atividades e continuidade das atividades da roundtable; com a pouca adesão de grandes produtores (EUA) e compradores mundiais de soja (China), e; com o surgimento de iniciativas potencialmente concorrentes como a Soja Plus, liderada por ex-membros da iniciativa (ABIOVE e APROSOJA). A combinação dessas fragilidades resultou em conflitos internos que dificultaram a construção da identidade do grupo, ancorada no modelo business to business como estratégia de ação. Além disso, a RTRS foi única dentre as três roundtables 
analisadas que não contou com participação ativa de agentes estatais. Esta ausência prejudicou, em alguma medida, o desempenho da iniciativa.

De maneira bem diferente, a RSB construiu sua identidade coletiva pautada sobre o conhecimento técnico e científico sustentado por incumbents que não são considerados membros internos, já que não detêm o poder de voto na tomada de decisão. No entanto, esses agentes tiveram as habilidades sociais necessárias para convencer os tomadores de decisão sobre suas concepções, haja vista a elaboração dos P\&C de Sustentabilidade e do sistema de certificação desenvolvidos por agentes externos à iniciativa; em sua maioria, composta por pesquisadores e acadêmicos. O investimento em estudos científicos e em ferramentas tecnológicas serviu como guia para buscar legitimidade diante do mercado internacional de biocombustíveis (biomateriais). Mesmo com a recente reestruturação da roundtable e desvinculação da EPFL, a RSB ainda orientou suas estratégias sobre o campo das pesquisas tecnológicas, dos conceitos científicos, das metodologias de análise e do monitoramento como um diferencial no mercado.

Já a partir da análise da RSPO, constatou-se que a iniciativa delineou sua identidade coletiva apoiada no tradicional modelo business to business, porém, sensível às questões socioambientais envolvidas ao longo da cadeia produtiva do óleo de palma. Amparada na importância da rastreabilidade do processo de produção como sua principal estratégia de ação, a roundtable traçou suas regras em torno destes critérios, servindo de base para a elaboração de seus P\&C de Sustentabilidade. Diferentemente das iniciativas aqui analisadas, a RSPO contou com a presença de três categorias de incumbents, além da forte coalizão política de representantes vinculados ao governo indonésio e malásio. Isso poderia representar intensos conflitos entre os participantes, resultando na cisão do grupo ou no surgimento de concorrentes, como ocorreu com a RTRS. A interferência de agentes estatais esteve presente em todos os encontros, ilustrada através do estreito envolvimento de agentes da Indonésia e Malásia na Comissão Executiva, na qual foram criados os cargos de membros honorários. Contudo, no lugar dos conflitos, o que foi observado é a forte coesão entre os participantes da RSPO no gerenciamento da iniciativa e no estabelecimento das estratégias de ação.

A partir dessas avaliações, constatou-se que ao revelar as concepções de controle que guiam o comportamento dos agentes e o SAF delineado em cada iniciativa, é possível identificar os agentes sociais e econômicos, caracterizando-os em incumbents e challengers por meio de suas habilidades sociais, coalizão política e organização dentro do campo de disputas. Também cabe destacar que as relações entre os membros internos sofreram significativa influência advinda daqueles que não são os tomadores de decisão no interior da arena de ação. No caso da RSPO, a participação de agentes estatais gerou maior coesão entre os envolvidos, e da RSB, a expertise de seus participantes externos foi o diferencial para destacar sua atividade no setor. Com isso, percebeu-se a relevância de se considerar a amplitude entre campos no processo de análise de iniciativas de governança privada.

Após análises, vale salientar que mesmo com a promessa em tratar os conflitos ambientais em torno da exploração e uso dos recursos naturais, esse tipo de arranjo possui importantes limitações. Talvez a principal delas esteja vinculada à necessidade da presença dos órgãos governamentais como entidades estruturadoras e reguladoras. Os agentes estatais não regulam, nem 
elaboram os critérios que regem a constituição e a ação das roundtables, mas são responsáveis pela organização dos setores produtivos, seja nos termos legais, seja no compartilhamento de informações. Assim, é possível notar a complexidade que os processos em governança privada possuem. Primeiro, por estarem estruturados sobre um novo arranjo institucional, gerenciado pelo setor privado e por representantes da sociedade sem a intervenção direta do Estado, e simultaneamente, imersos em um novo mercado que tem na ideia de sustentabilidade (tema polêmico e cercado de controvérsias, como é o caso dos biocombustíveis), a sua base de organização e funcionamento.

\section{REFERÊNCIAS}

ABRAMOVAY, Ricardo. How to design policies and institutions to make smallscale farmers benefit from bioenergy development. Preparatory Study for the FAO High Level Conference on Climate Change, Bioenergy and Food Security. São Paulo, 53p. 2008.

ONGs e setor privado buscam avanços em certificações ambientais. Valor Econômico, Agosto de 2010.

BAKER, Wayne.The Social Structure of a Securities Market. American Journal of Sociology. 89: 775-811. 1984.

BERNSTEIN, Steven. When is non-state global governance really governance? Utah Law Review, v. 2010, n. 1. 2010. Disponível em: $<$ http://epubs.utah.edu/index.php/ulr/article/viewArticle/347>. Acesso em março de 2011.

BOSCHI, Renato R. Descentralismo, clientelismo e capital social na governança urbana: comparando Belo Horizonte e Salvador. Dados. 42 (4). 1999.

BOURDIEU, Pierre. Le champ economique. Actes de la recherche en sciences sociales 119:48-66. 1997.

BOURDIEU, Pierre; WACQUANT, Loic. Invitation to a Reflexive Sociology. Chicago: University of Chicago Press. 1992.

BURT, Ronald. Corporate Profits and Cooptation. New York: Academic Press. 1983.

CASHORE, Benjamin. Legitimacy and the privatization of environmental governance: how non-state market-driven (NSMD) governance systems gain rule-making authority. 2002. Disponível em: http://www.yale.edu/forestcertification/pdfs/2002/02 new gove nmsd.pdf.

Acesso em março de 2011.

CASHORE, Benjamin; AULD, Graeme; NEWSON, Deanna Governing through markets: forest certification and the emergence of non-state authority. Yale University Press. 2004. 
DIMAGGIO, Paul. Interest and Agency in Institutional Theory. pp. 3-21 in Institutional Patterns and Organization, edited by Lynne G. Zucker. Cambridge, MA: Ballinger Press. 1988.

Culture and economy. pp. 22-57 in Neil J. Smelser and Richard Swedberg, eds. Handbook of Economic Sociology. Princeton N.J.: Princeton University Press. 1994.

DIMAGGIO, Paul; POWELL, Walter W. The iron cage revisited: institutional isomorphism and collective rationality in organizational fields. American Sociological Review, 48 (2), 147-160. 1983.

The New Institutionalism. pp. 3-45 in Organizational Theory, edited by W. Powell and P. DiMaggio. Chicago, IL: University of Chicago Press. 1991.

EMIRBAYER, Mustafa; JOHNSON, Victoria. Bourdieu and Organizational Analysis. Theory and Society 37:1-44. 2008.

FAO. Food and Agriculture Organization of the United Nations. Smallholder integration in changing food markets. 2013. Disponível em: $<$ http://www.fao.org/docrep/018/i3292e/i3292e.pdf >. Acesso em outubro de 2013.

FLIGSTEIN, Neil. The Intraorganizational Power Struggle: the Rise of Finance residents in Large Corporations. American Sociological Review 52:44-58. 1987.

. The Transformation of Corporate Control. Cambridge, MA.: Harvard University Press. 1990.

Market as politics: a political-cultural approach to market institutions. American Sociological Review, v. 61, 656-673. 1996.

Social Skill and the Theory of Fields. Sociological Theory, v.19, n. 2. 205-125. 2001.

The Architecture of Markets: an economic sociology of twentyfirst-century capitalist societies. Princeton: Princeton University Press. 2002.

FLIGSTEIN, Neil; McADAM, Doug. Toward a General Theory of Strategic Action Fields. Sociological Theory. 29:1. 2011.

A Theory of Fields. Oxford University Press. 2012.

GAMSON, William. The Strategy of Social Protest. Homewood, IL: Dorsey Press. 1975.

GEERTZ, Clifford. Local Knowledge. New York: Basic Books. 1983. 
GRANOVETTER, Mark. Economic Action, Social Structure and Embeddedness. American Journal of Sociology 91: 481-510. 1985.

Economic Institutions as Social Constructions: A Framework for

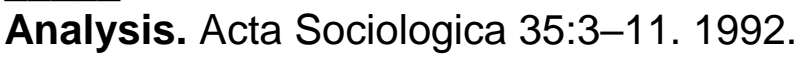

- The Impact of Social Structure on Economic Outcomes. Journal of Economic Perspectives, 19(1): 33-50. 2005.

HOSPES, Otto; VALK, Olga Van der; MHEEN, Jennie Van der. Parallel development of five partnerships to promote sustainable soy in Brazil: solution or part of wicked problems? International Food and Agribusiness Management Review,15: p.29-52. 2012.

JASPER, James. A Strategic Approach to Collective Action. Mobilization 9:1-16. 2004.

JASPER, James. Getting Your Way: Strategic Dilemmas in the Real World. Chicago: University of Chicago Press. 2006.

$\mathrm{MARCH}$, James. The Firm as a Political Coalition. Administrative Science Quarterly 2: 23-41. 1961.

MARTIN, John. What is Field Theory? American Journal of Sociology 109:149. 2003.

McADAM, Doug. Political Process and the Development of Black Insurgency. Chicago, IL: University of Chicago Press. 1982.

McADAM, Doug; SCOTT, W. Richard. Organizations and Movements. Pp. 440 in Social Movements and Organization Theory, edited by Gerald F. Davis, Doug McAdam, W. Richard Scott, and Mayer N. Zald. Cambridge, UK: Cambridge University Press. 2005.

McCARTHY, John; ZALD, Mayer. 1973. The Trend of Social Movements in America: Professionalization and Resource Mobilization. Morristown, NJ: General Learning Press.

O'ROURKE, Dara. Multi-stakeholder regulation: privatizing or socializing global labor standards? World Development v.34. 5:899-918. 2006.

OSTROM, Elinor. Governing the commons: the evolution of institutions for collective action. Cambridge University Press. 1990.

2005

Understanding Institutional Diversity. Princeton University Press. 
POWELL, Walter; SMITH-DOERR, Laurel. Networks and Economic life. Pp. 368-403 in The Handbook of Economic Sociology, edited by N. Smelser and R. Swedburg. New York: Russell Sage. 1994.

RSB. Roundtable on Sustainable Biofuels. Board of Directors Meetings. Meeting Report. 2011. Disponível em: <http://rsb.org/steering-boardmeetings/>. Acesso em outubro de 2012.

RSB. Roundtable on Sustainable Biofuels. Governance Structure and Organization. 2013. Disponível em: <http://rsb.org/about/organization/>. Acesso em março de 2013.

RSPO. Roundtable on Sustainable Palm Oil. Organization Structure. 2012. Disponível em: <http://www.rspo.org/en/organization structure>. Acesso em março de 2013.

RTRS. Roundtable on Responsible Soy. Governança. Disponível em: $<$ http://www.responsiblesoy.org/index.php?option=com content\&view=article\&i $\mathrm{d}=14 \&$ Itemid=15\&lang=pt\#>. Acesso em janeiro de 2012.

SCHOUTEN, Greetje; GLASBERGEN, Pieter. 2011. Creating legitimacy in global private governance: The case of the Roundtable on Sustainable Palm Oil. Ecological Economics. 70: 1891-1899.

SOJA PLUS. Environmental, Social and Economic Management Program for Brazilian Soybeans. 2013. Organization. Disponível em: <http://www.sojaplus.com.br/index us.html>. Acesso em janeiro de 2013.

SPILMANN, Lyn. Enriching Exchange: Cultural Dimensions of Markets. American Journal of Economics and Sociology, Vol. 58, No. 4: pp. 1047-1071. 1999.

SMELSER, Neil J.; SWEDBERG, Richard. The handbook of economic sociology. 2nd ed. Princeton University Press. 2005.

SNOW, David; ROCHFORD, E. Burke; WORDEN, Steven; BENFORD, Robert. Frame Alignment and Mobilization. American Sociological Review 51:464-81. 1986.

SUCHMAN, Mark C. Managing Legitimacy: Strategic and Institutional Approaches. Academy of Management Review. v.20, 571-610. 1995.

SWEDBERG, Richard; GRANOVETTER, Mark. The Sociology of Economic Life. Boulder, Colo: Westview Press. 1992.

TARROW, Sidney. Power in Movement. Cambridge, England: Cambridge University Press. 1994.

TENDLER, Judith. Bom governo nos trópicos: uma visão crítica. Ed. Revan. 1998. 
VALLEJO, Nancy; HAUSELMANN, Pierre. Governance and multistakeholder processes. International Institute for Sustainable Development. 2004.

WHITE, Harrison. Where Do Markets Come From? American Journal of Sociology. 87:517-47. 1981.

WILLIAMSON, Oliver E. Markets and Hierarchies: Analysis and Antitrust Implications. New York: Free Press. 1975.

- Comparative economic organization. Administrative Science Quarterly 36: 269-96. 1991.

ZELIZAR, Viviana. Markets and Morals. Princeton, N.J: Princeton University Press. 1983.

Beyond the polemics on the market: establishing a theoretical and empirical agenda. Sociological Forum. 3: 614-34. 1988.

ZUKIN, Sharon; DIMAGGIO, Paul. Structures of Capital: The Social Organization of the Economy. Cambridge: Cambridge University Press.1990.

ZYLBERSZTAJN, Decio; FARINA, Elizabeth. Dynamics of network governance: a contribution to the study of complex forms. In: Revista Eletrônica de Administração. 16: 1. pp. 1-19. 2008.

Submetido em: 08/11/15

Aceito em: 09/12/15 